\title{
Scientific Publications on Portal Vein Thrombosis and Budd- Chiari Syndrome: a Global Survey of the Literature
}

\author{
Xingshun Qi ${ }^{1,2}$, Jia Jia ${ }^{1}$, Weirong Ren ${ }^{1}$, Man Yang $^{1}$, Valerio De Stefano ${ }^{3}$, Juan Wang ${ }^{2}$, Daiming Fan ${ }^{1}$
}

1) Xijing Hospital of Digestive

Diseases, Fourth Military

Medical University, Xi'an;

2) Department of

Gastroenterology, No. 463

Hospital of Chinese PLA,

Shenyang, China;

3) Institute of Hematology,

Catholic University, Rome,

Italy

\author{
Address for correspondence: \\ Daiming Fan \\ Xijing Hospital of Digestive \\ Diseases \\ Fourth Military Medical \\ University \\ No. 27 West Changle Road, \\ Xi'an, 710032, China \\ fandaim@fmmu.edu.cn
}

Received: 13.12.2013

Accepted: 24.02.2014

\begin{abstract}
Background \& Aims: Portal vein thrombosis (PVT) and Budd-Chiari syndrome (BCS) are two rare vascular disorders of the liver that can lead to life-threatening complications. We conducted a global survey to systematically analyze the scientific publications in the fields of PVT and BCS.

Methods: All papers regarding PVT and BCS were identified via the PubMed, EMBASE, and Cochrane library databases. The publication year, country, type of paper, study design, and number of citations were summarized. Good quality papers were defined as those in which a high proportion of homogeneous patients with BCS and/or PVT was observed.

Results: We identified 6691 and 4325 papers regarding PVT and BCS, respectively. The number of papers gradually increased over time. Researchers from the USA published the greatest number of papers (PVT: $\mathrm{n}=1418$; BCS: $\mathrm{n}=888$ ). Clinical studies were the most common type of paper (PVT: $n=5395$; BCS $n=3171$ ), but fewer than half of these observed more than 10 patients (PVT: $n=2667 / 5395 ; B C S: n=1092 / 3171$ ). Furthermore, fewer than half of the clinical studies with more than 10 patients were of good quality (PVT: 976/2667; BCS: 466/1092). According to the study design, the good quality papers were classified as cohort studies (PVT: $\mathrm{n}=865$; BCS: $\mathrm{n}=421$ ), case-control studies (PVT: $\mathrm{n}=98$; BCS: $\mathrm{n}=45$ ), and randomized controlled trials (PVT: $\mathrm{n}=13 ; \mathrm{BCS}: \mathrm{n}=0$ ). The 5 most frequently cited original articles and guidelines/consensuses were also listed. Conclusions: Despite an increase in the number of papers regarding PVT and BCS over time, most of the papers had a small sample size, suggesting the necessity of large cohort studies or randomized controlled trials.
\end{abstract}

Key words: scientific publication - portal vein thrombosis - Budd-Chiari syndrome.

\section{INTRODUCTION}

Portal vein thrombosis (PVT) and Budd-Chiari syndrome (BCS) are two rare vascular disorders of the liver $[1,2]$. In the general population, the incidence of PVT is approximately $4 / 1,000,000$ every year [3], and its prevalence is about $1 \%$ [4]; the incidence of BCS is 0.1 $0.8 / 1,000,000$ every year [3, $5-6]$, and its prevalence is 1.4 $2.4 / 1,000,000$ [5-7]. The rarity of these diseases potentially limits us from performing largescale studies $[1,2]$. Notably, the diseases often lead to lethal portal hypertension-related complications and liver failure [1, $2]$, thereby severely influencing the patients' survival. Thus, research is required to explore the pathogenesis, diagnosis, prognosis, and treatment of the two diseases.

Scientific publications can rapidly and widely convey updated information and knowledge to physicians worldwide, and this information can be incorporated into the standard of care and potentially influence clinical practice in the future. The quantity of scientific publications can reflect the advances in the study fields of PVT and BCS. However, until now, information regarding the type and amount of literature related to PVT and BCS reported in different regions is still lacking. Herein, we conducted a global survey of the literature to systematically analyze the quantity of scientific publications regarding PVT and BCS in three major databases (PubMed, EMBASE, and Cochrane library).

\section{METHODS}

\section{Literature identification}

The PubMed, EMBASE, and Cochrane library databases were searched (from database inception to November 12, 
2012). Our search strategy aimed to maximize the quantity of retrieved literature. The search items were discussed with all review authors. For the PVT literature, the search items were (portal vein thrombosis) OR (portal venous thrombosis) OR (portal vein obstruction) OR (portal venous obstruction). For the BCS literature, the search items were (Budd Chiari) OR (hepatic vein obstruction) OR (hepatic venous obstruction) OR (hepatic vein thrombosis) OR (hepatic venous thrombosis) [8].

Papers regarding PVT and BCS were considered eligible for our survey based on the following conditions: 1) for original articles, the target population should PVT or BCS patients; and 2) for reviews and comments, PVT or BCS should be mentioned or discussed. Other eligibility criteria were as follows: 1) duplicates among the three databases were excluded [8]; 2) duplicate publications of one study were excluded [8]; 3) the type of article was not restricted (e.g., review, commentary, basic or clinical study); 4) the publication type was not restricted (abstract or full-text); 5) the publication language was not restricted (English language or others); 6) the publication date was not restricted (since database inception); and 7) either the primary or secondary disease was included. Duplicates and irrelevant literature were identified by four review authors and thus excluded. JJ and YM were responsible for the PVT literature, and QX and RW were responsible for the BCS literature [8]. If we were uncertain about whether papers should be included, the full texts were obtained. QX and YM were also responsible for rechecking the accuracy of their tasks. Disagreement would be resolved by discussion among the four review authors.

\section{Classifications and definitions}

We further identified the publication year, corresponding or first author's country, number of journals, level of journals, specialty of journals, and type of article.

The levels of journals were mainly divided into high, middle, and low levels. Journals were considered high-level if they were listed in the Science Citation Index Expanded (SCIE) subject categories by the Institute for Scientific Information (ISI) and had an impact factor greater than 5 according to the Journal Citation Reports (JCR) 2011. Journals were considered middle-level, if they were listed in the SCIE subject categories and had an impact factor less than 5 according to the JCR 2011. Journals were considered low-level, if they were not listed in the SCIE subject categories.

The specialties of journals were classified as Internal \& General Medicine, Surgery, Radiology, Hematology, Gastroenterology and Hepatology, and Others.

The types of articles were mainly classified as review (including narrative and systematic review), commentary (including comment, editorial, interview, and erratum), basic study (including experimental and animal study), and clinical study (including clinical study with a small and large sample size). A small sample size was defined as fewer than 10 patients. If we were uncertain about the type of articles, the full texts would be obtained.

According to the study population included in each piece of literature, papers describing clinical studies with more than 10 patients were classified as "good" or "poor" quality papers.
Good quality papers were defined as studies that included a high proportion of homogeneous groups of patients with BCS and/or PVT. Otherwise, the papers were considered to be of poor quality.

According to the study design, the good quality clinical studies were classified as cohort studies, case-control studies, and randomized controlled trials. Furthermore, the good quality studies were divided into six topics: pathogenesis (including risk factors, etiology, and hemodynamics), diagnosis (including clinical, radiological, and pathological diagnosis), management (including safety, efficacy, and outcome of various treatment modalities and perioperative management), prognosis, other topic, and mixed topic.

Additionally, QX examined the number of citations of original articles regarding PVT and BCS using Google Scholar (http://www.scholar.google.com) in April 2013.

\section{Data analysis}

The count data and/or percentage were reported in texts and/or charts. The trend regarding the number of articles over time was presented in line charts, and the proportion of articles according to the level and specialty of journals and type of papers was presented in pie charts. All analyses were performed using the SPSS 16.0 statistical software (Chicago, IL, USA).

\section{RESULTS}

\section{Portal vein thrombosis}

Overall, 10,936 papers were identified by our search strategy. After duplicate and irrelevant papers were excluded, 6691 papers regarding PVT were included in our study (Fig. 1A). The number of papers gradually increased over time (Fig. 2).

All included papers were reported by researchers from 84 countries (Fig. 3A). Researchers from the USA published the greatest number of papers $(n=1418,21.2 \%)$, followed by those from Japan $(n=880,13.2 \%)$, France $(n=524,7.8 \%)$, China $(\mathrm{n}=497,7.4 \%)$, and Italy $(\mathrm{n}=466,7.0 \%)$. Before 2000 , China had the fewest number of papers among these 5 countries. After 2001, the number of papers from China ranked third, exceeding those from France and Italy (Fig. 4A).

The types of papers included 827 (12.4\%) reviews, 227 (3.4\%) commentaries, $242(3.6 \%)$ basic studies, and 5395 (80.6\%) clinical studies. Notably, 50.6\% (2728/5395) and 49.4\% (2667/5395) of the clinical studies had small and large sample sizes, respectively.

The clinical studies with more than 10 patients were reported by researchers from 71 countries. The top 5 countries were the USA $(n=481)$, Japan $(n=293)$, China $(n=250)$, India $(\mathrm{n}=198)$, and Italy $(\mathrm{n}=197)$. Before 1980 , no clinical study with more than 10 patients was published in China. After 1981, the number of clinical studies with greater than 10 patients in China markedly increased over time (Fig. 5A).

Among the clinical studies with more than 10 patients, 976 and 1691 papers were identified as good and poor quality studies, respectively. The good quality studies included 865 cohort studies, 98 case-control studies, and 13 randomized controlled trials. Additionally, they were classified as 191 papers 
A

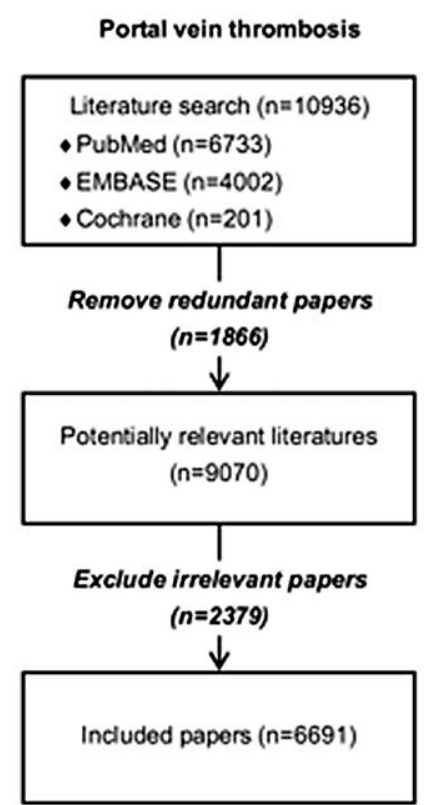

B

\section{Budd-Chiari syndrome}

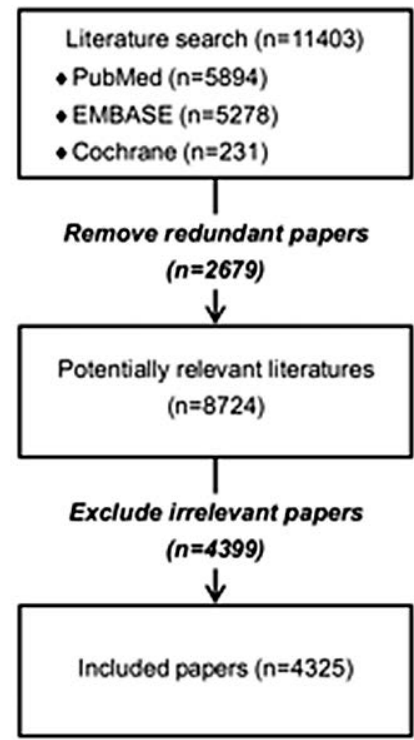

Fig. 1. Study flowchart of the literature. Panel A. Literature regarding portal vein thrombosis. Panel B. Literature regarding Budd-Chiari syndrome.

on pathogenesis, 165 on diagnosis, 365 on management, 62 on prognosis, 63 on other topics, and 130 papers on mixed topics.

\section{Budd-Chiari syndrome}

Overall, 11,402 papers were identified by our search strategy. After duplicate and irrelevant papers were excluded, 4325 papers regarding BCS were included in our study (Fig. 1B). The number of papers gradually increased over time (Fig. 2).

The included papers were reported by authors from 78 countries (Fig. 3B). The greatest number of papers were published by USA authors ( $\mathrm{n}=888,20.5 \%)$, followed by authors form France $(\mathrm{n}=424,9.8 \%)$, Japan $(\mathrm{n}=406,9.4 \%)$, Germany $(n=306,7.1 \%)$, and China $(n=299,6.9 \%)$. Before 2000, China had the fewest number of papers among these 5 countries. After 2001, the number of papers from China ranked second (Fig. 4B).

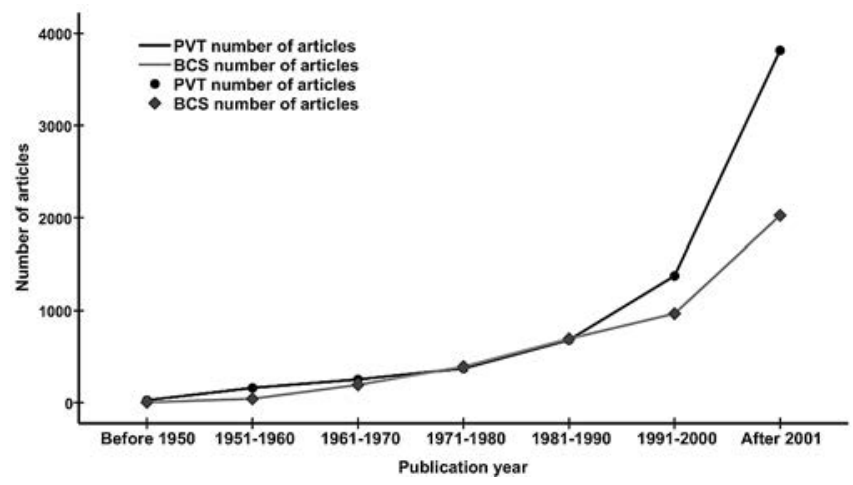

Fig. 2. Number of papers regarding portal vein thrombosis (black line) and Budd-Chiari syndrome (grey line) according to the publication year.

PVT, portal vein thrombosis; BCS, Budd-Chiari syndrome.
The types of papers included 830 (19.2\%) reviews, 230 (5.3\%) commentaries, 94 (2.2\%) basic studies, and 3171 (73.3\%) clinical studies. Notably, 65.6\% (2079/3171) and 34.4\% (1092/3171) of the clinical studies had small and large sample sizes, respectively.

The clinical studies with more than 10 patients were reported from 58 countries. The top 5 countries were China $(n=159)$, the USA $(n=152)$, France $(n=87)$, India $(n=80)$, and United Kingdom ( $n=77$ ). Before 1980, no clinical study with greater than 10 patients was published in China. After 1981, the number of clinical studies with greater than 10 patients in China gradually increased over time (Fig. 5B).

Among the clinical studies with more than 10 patients, 466 and 626 papers were identified as good and poor quality studies, respectively. The good quality studies included 421 cohort studies and 45 case-control studies, but no randomized controlled trial was reported. Additionally, the studies were classified as 79 papers on pathogenesis, 88 on diagnosis, 208 on management, 11 on prognosis, 20 on other topics, and 60 papers on mixed topics.

\section{Highly cited papers}

According to the number of citations, the 5 most frequently cited original articles regarding PVT and BCS are listed in Table I. The greatest number of citations was less than 500 , regardless of the publication year. The consensuses and practice guidelines regarding PVT and/or BCS produced by scientific societies and ad hoc panels of experts are listed in Table II.

\section{DISCUSSION}

To our knowledge, this is the first study to systematically analyze the quantity of literature regarding PVT and BCS in the PubMed, EMBASE, and Cochrane library databases 

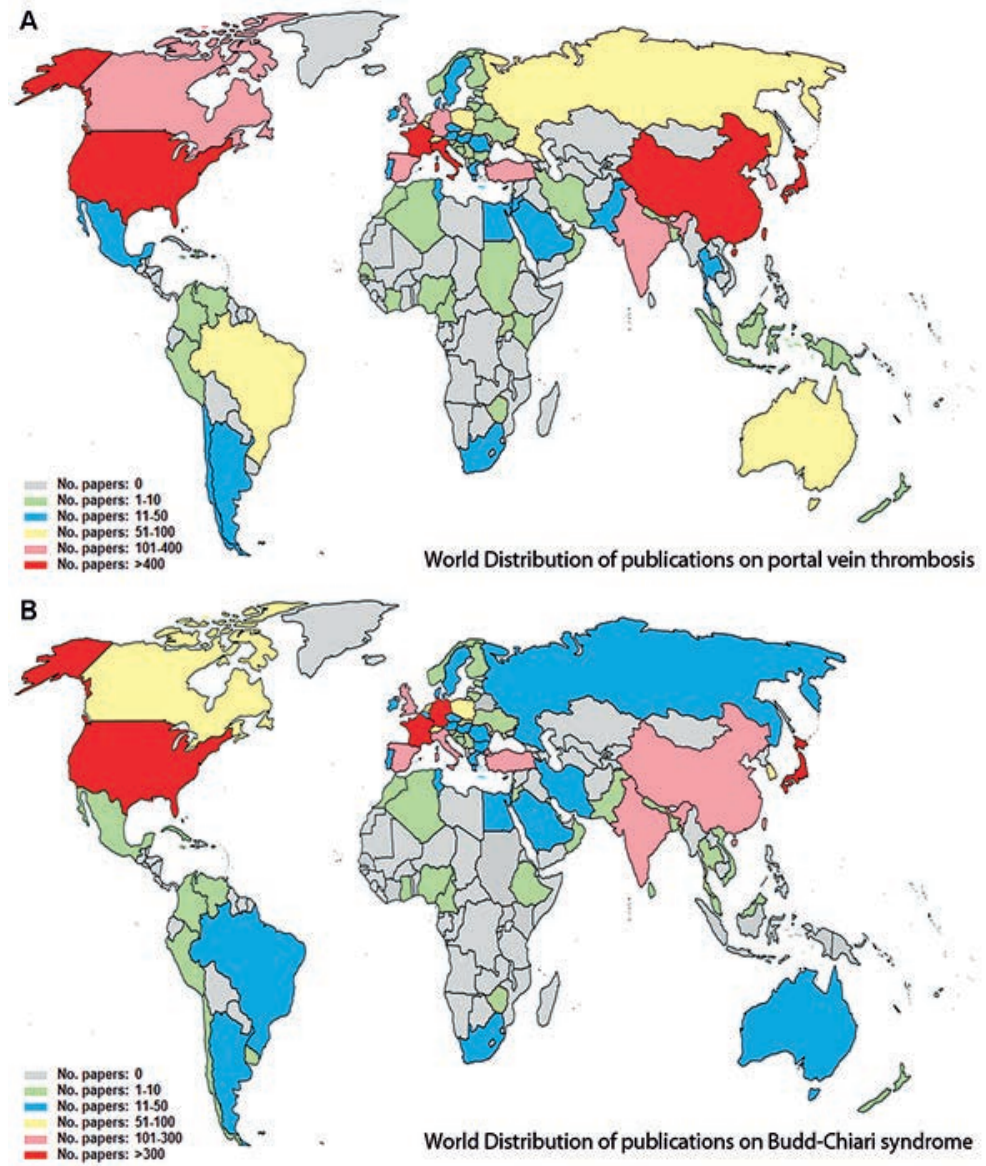

Fig. 3. World distribution of publications in the PubMed, EMBASE, and Cochrane library databases. A. Publications regarding portal vein thrombosis. B. Publications regarding Budd-Chiari syndrome.
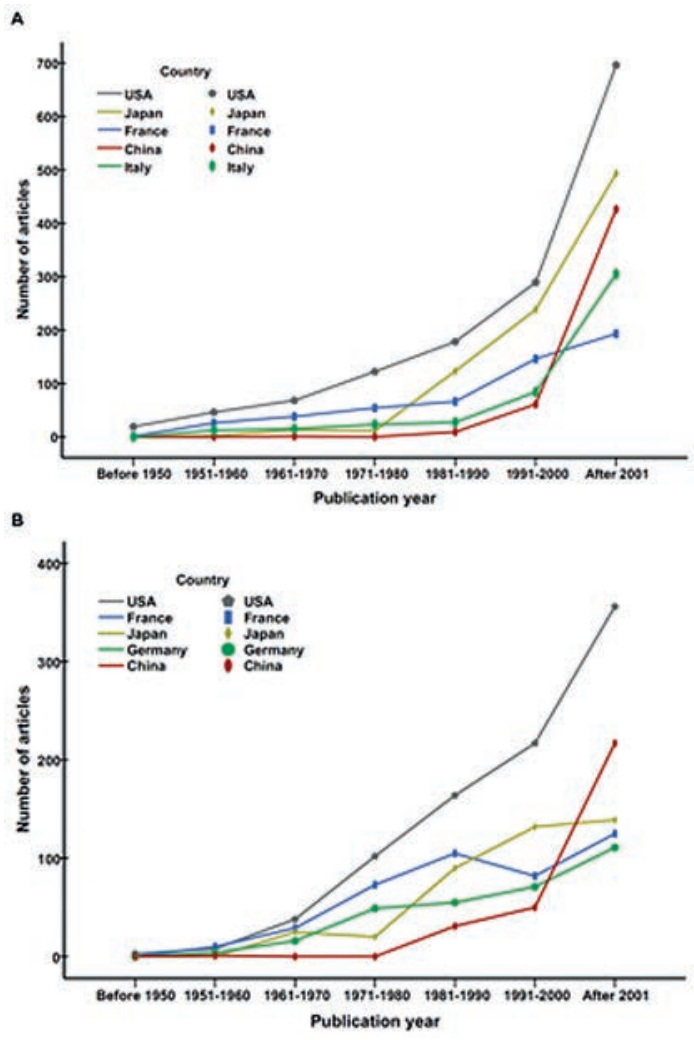

Fig. 4. Number of total papers in the top 5 countries according to the publication year. A. Papers regarding portal vein thrombosis. B. Papers regarding Budd-Chiari syndrome.
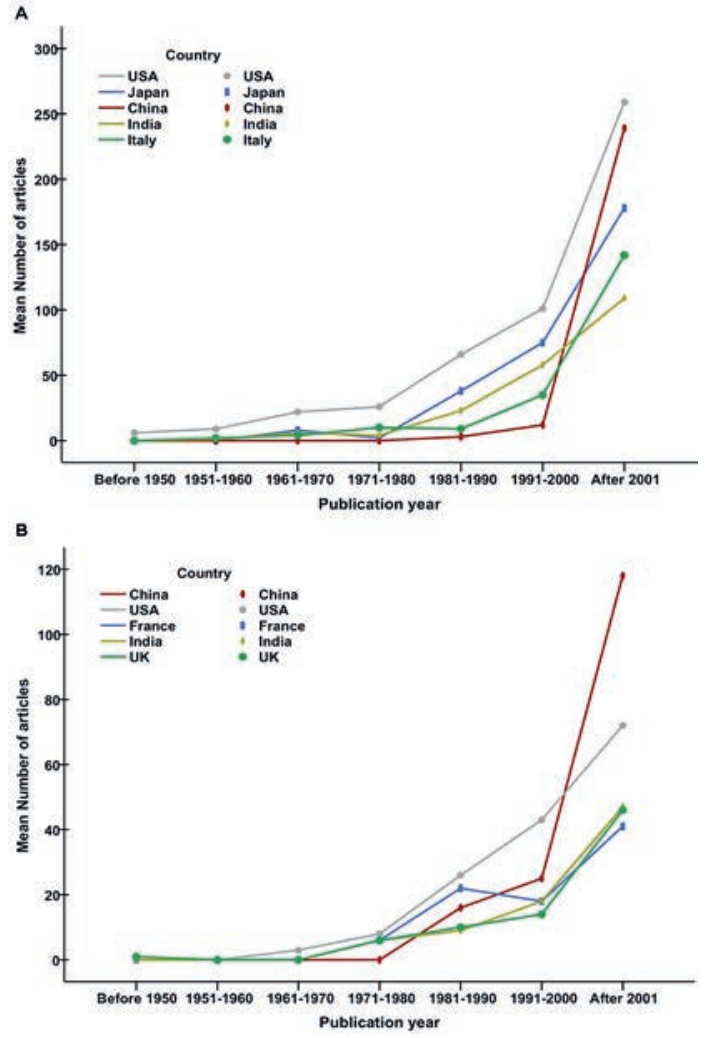

Fig. 5. Number of clinical studies with more than 10 patients in the top five countries according to the publication year. A. Papers regarding portal vein thrombosis. B. Papers regarding Budd-Chiari syndrome. 
Table I. Top five most cited original articles regarding portal vein thrombosis and Budd-Chiari syndrome

\begin{tabular}{|c|c|}
\hline Articles & Citations \\
\hline \multicolumn{2}{|l|}{ Portal vein thrombosis } \\
\hline $\begin{array}{l}\text { Denninger MH, Chait Y, Casadevall N, Hillaire S, Guillin MC, Bezeaud A, et al. Cause of portal or hepatic } \\
\text { venous thrombosis in adults: The role of multiple concurrent factors. Hepatology. 2000;31(3):587-91. }\end{array}$ & 443 \\
\hline $\begin{array}{l}\text { Okuda K, Ohnishi K, Kimura K, Matsutani S, Sumida M, Goto N, et al. Incidence of portal vein thrombosis in } \\
\text { liver cirrhosis. An angiographic study in } 708 \text { patients. Gastroenterology. 1985;89(2):279-86. }\end{array}$ & 272 \\
\hline $\begin{array}{l}\text { Janssen HL, Meinardi JR, Vleggaar FP, van Uum SH, Haagsma EB, Van Der Meer FJ, et al. Factor V Leiden } \\
\text { mutation, prothrombin gene mutation, and deficiencies in coagulation inhibitors associated with Budd-Chiari } \\
\text { syndrome and portal vein thrombosis: Results of a case-control study. Blood. 2000;96(7):2364-8. }\end{array}$ & 267 \\
\hline $\begin{array}{l}\text { Condat B, Pessione F, Hillaire S, Denninger MH, Guillin MC, Poliquin M, et al. Current outcome of portal } \\
\text { vein thrombosis in adults: Risk and benefit of anticoagulant therapy. Gastroenterology. 2001;120(2):490-7. }\end{array}$ & 262 \\
\hline $\begin{array}{l}\text { Condat B, Pessione F, Denninger MH, Hillaire S, Valla DC. Recent portal or mesenteric venous thrombosis: } \\
\text { Increased recognition and frequent recanalization on anticoagulant therapy. Hepatology. 2000;32(3):466-70. }\end{array}$ & 251 \\
\hline \multicolumn{2}{|l|}{ Budd-Chiari syndrome } \\
\hline $\begin{array}{l}\text { Denninger MH, Chait Y, Casadevall N, Hillaire S, Guillin MC, Bezeaud A, et al. Cause of portal or hepatic } \\
\text { venous thrombosis in adults: The role of multiple concurrent factors. Hepatology. 2000;31(3):587-91. }\end{array}$ & 443 \\
\hline $\begin{array}{l}\text { Janssen HL, Meinardi JR, Vleggaar FP, van Uum SH, Haagsma EB, van Der Meer FJ, et al. Factor V Leiden } \\
\text { mutation, prothrombin gene mutation, and deficiencies in coagulation inhibitors associated with Budd-Chiari } \\
\text { syndrome and portal vein thrombosis: results of a case-control study. Blood. 2000;96(7):2364-8. }\end{array}$ & 267 \\
\hline $\begin{array}{l}\text { Dilawari JB, Bambery P, Chawla Y, Kaur U, Bhusnurmath SR, Malhotra HS, et al. Hepatic outflow } \\
\text { obstruction (Budd-Chiari syndrome). Experience with } 177 \text { patients and a review of the literature. Medicine. } \\
\text { 1994;73(1):21-36. }\end{array}$ & 265 \\
\hline $\begin{array}{l}\text { Valla DC, Casadevall N, Lacombe C, Varet B, Goldwasser E, Franco D, et al. Primary myeloproliferative } \\
\text { disorder and hepatic vein thrombosis. A prospective study of erythroid colony formation in vitro in } 20 \\
\text { patients with Budd-Chiari syndrome. Ann Intern Med. 1985;103(3):329-34. }\end{array}$ & 261 \\
\hline $\begin{array}{l}\text { Patel RK, Lea NC, Heneghan MA, Westwood NB, Milojkovic D, Thanigaikumar M, et al. Prevalence of } \\
\text { the activating JAK2 tyrosine kinase mutation V617F in the Budd-Chiari syndrome. Gastroenterology. } \\
\text { 2006;130(7):2031-8. }\end{array}$ & 201 \\
\hline
\end{tabular}

Table II. Practice guidelines and consensus regarding portal vein thrombosis and Budd-Chiari syndrome produced by scientific societies and ad hoc panel of experts

\begin{tabular}{|c|c|}
\hline Articles & Societies or Groups \\
\hline $\begin{array}{l}\text { Janssen HL, Garcia-Pagan JC, Elias E, Mentha G, Hadengue A, Valla DC. Budd- } \\
\text { Chiari syndrome: a review by an expert panel. J Hepatol. } 2003 \text { Mar;38(3):364-71. }\end{array}$ & $\begin{array}{l}\text { European Group for the Study of } \\
\text { Vascular Disorders of the Liver }\end{array}$ \\
\hline $\begin{array}{l}\text { Sarin SK, Sollano JD, Chawla YK, Amarapurkar D, Hamid S, Hashizume M, } \\
\text { et al. Consensus on extra-hepatic portal vein obstruction. Liver Int. } 2006 \\
\text { Jun;26(5):512-9. }\end{array}$ & $\begin{array}{l}\text { Asian Pacific Association for Study of } \\
\text { the Liver }\end{array}$ \\
\hline $\begin{array}{l}\text { Senzolo M, Riggio O, Primignani M. Vascular disorders of the liver: } \\
\text { recommendations from the Italian Association for the Study of the Liver (AISF) } \\
\text { ad hoc committee. Dig Liver Dis. } 2011 \text { Jul;43(7):503-14. }\end{array}$ & $\begin{array}{l}\text { Italian Association for the Study of } \\
\text { the Liver }\end{array}$ \\
\hline $\begin{array}{l}\text { DeLeve LD, Valla DC, Garcia-Tsao G. Vascular disorders of the liver. } \\
\text { Hepatology. } 2009 \text { May;49(5):1729-64. }\end{array}$ & $\begin{array}{l}\text { American Association for the Study of } \\
\text { Liver Diseases }\end{array}$ \\
\hline $\begin{array}{l}\text { De Franchis R. Evolving Consensus in Portal Hypertension Report of the } \\
\text { Baveno IV Consensus Workshop on methodology of diagnosis and therapy in } \\
\text { portal hypertension. Journal of Hepatology. 2005;43(1):167-76. }\end{array}$ & Baveno Consensus Workshop \\
\hline $\begin{array}{l}\text { De Franchis R. Revising consensus in portal hypertension: Report of the Baveno } \\
\mathrm{v} \text { consensus workshop on methodology of diagnosis and therapy in portal } \\
\text { hypertension. Journal of Hepatology. 2010;53(4):762-8. }\end{array}$ & Baveno Consensus Workshop \\
\hline
\end{tabular}

since each database's inception. Our study demonstrated a gradually increasing trend in the number of papers regarding PVT and BCS, and the number of papers published every year after 2009 became markedly larger. This finding suggests the growing awareness of the importance of these two diseases and the persistent advance of the relevant knowledge. However, compared with the literature regarding common liver diseases (e.g., viral hepatitis and liver cirrhosis), the total number of papers regarding PVT and BCS was remarkably smaller, and the speed of research progress was relatively slower. Recently, Wang and colleagues have systematically analyzed the number of original research papers regarding liver cirrhosis and portal hypertension in six SCI Hepatology specialized journals [9]. These authors found that the proportion of original research papers regarding PVT and BCS among all papers regarding portal hypertension was very small. Compared with this previous study, in which the investigators searched six SCI journals in the field of liver diseases, we employed a more 
extensive search strategy by using three major databases. Despite this, we still found only a small number of clinical studies with greater than 10 patients, especially good quality papers. This was primarily due to a low prevalence of PVT and BCS and fewer government and corporate grants for these studies.

Another finding was that these papers were from many parts of the world, suggesting that researchers/physicians worldwide have attached great importance to the study fields of PVT and BCS. However, most of the papers were from developed countries. Authors from the USA were responsible for more than $20 \%$ of the literature regarding PVT and BCS in the PubMed, EMBASE, and Cochrane library databases. It should be noted that many journals from non-English speaking countries might not be indexed in these databases. For example, a total of 299 Chinese papers regarding BCS were retrieved in the present study; in comparison, 1914 Chinese papers regarding BCS were found in a previous study that searched the PubMed and two Chinese language journal databases (i.e., the Chinese Scientific and Technological Journal database and the China National Knowledge Infrastructure database) [10]. In addition, we identified the level and specialty of journals in which these papers were published (see Supplementary Materials). Notably, a greater number of papers were published in SCI journals with an impact factor less than 5 and in Gastroenterology/Hepatology and Surgery specialized journals.

Finally, our study demonstrated that clinical studies were the most common type of paper in the fields of PVT and BCS. More importantly, more than one half of the clinical studies were case reports with a sample size of less than 10 patients, and no randomized controlled trial had been performed in patients with BCS. This finding suggested that the existing evidence was of low quality. We also summarized the 5 most frequently cited original articles in the two fields. Undoubtedly, these critical articles covered the most important information in the research field and were of great importance to give guidelines to clinical practice. Notably, the Clichy group from France published the greatest number of frequently cited articles [1116]. In comparison, several large-scale studies regarding the treatment of BCS in China had a relatively smaller number of citations. For example, one multi-center study conducted by Wang et al in 2005, in which 2677 Chinese BCS patients were treated by surgery and/or interventional procedures [17], was cited 75 times; another single-center study conducted in 2004, in which 1360 Chinese BCS patients were treated by surgery [18], was cited 50 times. This finding might be explained by the following points: 1) these studies were of low quality and involved less detailed information and a shorter follow-up; 2) surgery has been gradually replaced by interventional therapy in the treatment of BCS [19]; and 3) the studies' conclusions might be difficult to extrapolate to Western patients due to the difference in the mechanism of BCS $[20,21]$.

Our study had several limitations. First, we were afraid that many non-English language papers might be omitted, despite employing three databases that are commonly used in systematic reviews. Thus, the actual number of papers regarding PVT and BCS, especially those from non-English speaking countries, might be underestimated. Second, the exclusion of irrelevant literature was a complex and time-consuming process. In our study, four review authors (QX, RW, YM, and JJ) spent more than one month finding irrelevant literature by reading the titles and abstracts, and one review author (QX) spent another two months on rechecking the accuracy of these tasks by reading the full texts. However, we had to acknowledge that the full texts of a very small portion of older literature could not be obtained, so not all included literature might be completely eligible. Third, it was very difficult to perform a strict assessment of study quality. Indeed, no pre-existing, well-established methods could be employed to assess the study quality. More importantly, the topics discussed in this set of literature (pathogenesis, diagnosis, treatment, prognosis, other topic, and mixed topic) and the types of study designs (e.g., case report, case series, cohort, case-control, randomized controlled trials) were so different that a unified criterion was unavailable. Among the similar studies previously published [22-23], none assessed the quality of the study.

\section{CONCLUSIONS}

In conclusion, this global survey of literature, which involved searching the PubMed, EMBASE, and Cochrane library databases, demonstrated the gradually increasing importance of PVT and BCS research worldwide. Researchers from the USA contributed wtih the greatest number of papers regarding these two diseases. Notably, the amount of literature from China has markedly increased over time. The 5 most frequently cited original articles and practice guidelines/consensuses produced by scientific societies and ad hoc panels of experts were also listed in the survey. These papers were of great importance to guide clinical practice. The absence of randomized controlled trials regarding BCS suggests that the quality of the current evidence regarding the treatment strategy of BCS was low and that more high-level studies should be conducted.

Conflicts of interest. The authors disclose no potential conflicts of interest for this study. The authors also disclose no financial support for this study.

Acknowledgements. The results regarding the number of relevant papers according to the levels and specialties of journals can be found in the Supplementary Materials (http://www.jgld.ro/2014/1/ supplementary-material-jgld-23-1.doc).

Authors' contributions. Dr. Qi had full access to all of the data in the study and takes responsibility for the integrity of the data and the accuracy of the data analysis. Study concept and design: Qi; acquisition of data: Qi, Jia, Ren, Yang; analysis and interpretation of data: Qi, Jia, Ren, Yang, De Stefano, Wang, Fan; drafting of the manuscript: Qi; critical revision of the manuscript for important intellectual content: Qi, Ren, De Stefano, Jia, Yang, Wang, Fan; study supervision: Qi, Fan. The first four authors contributed equally to this work.

\section{REFERENCES}

1. DeLeve LD, Valla DC, Garcia-Tsao G; American Association for the Study Liver Diseases. Vascular disorders of the liver. Hepatology 2009;49:1729-1764. 
2. De Stefano V, Martinelli I. Splanchnic vein thrombosis: clinical presentation, risk factors and treatment. Intern Emerg Med 2010;5:487-494.

3. Almdal TP, Sorensen TI. Incidence of parenchymal liver diseases in Denmark, 1981 to 1985: analysis of hospitalization registry data. The Danish Association for the Study of the Liver. Hepatology 1991;13:650-655.

4. Ogren M, Bergqvist D, Bjorck M, Acosta S, Eriksson H, Sternby NH. Portal vein thrombosis: prevalence, patient characteristics and lifetime risk: a population study based on 23,796 consecutive autopsies. World J Gastroenterol 2006;12:2115-2119.

5. Valla DC. Hepatic venous outflow tract obstruction etiopathogenesis: Asia versus the West. J Gastroenterol Hepatol 2004;19 Suppl 7:S204-S211.

6. Rajani R, Melin T, Bjornsson E, et al. Budd-Chiari syndrome in Sweden: epidemiology, clinical characteristics and survival - an 18-year experience. Liver Int 2009;29:253-259.

7. Okuda H, Yamagata H, Obata $H$, et al. Epidemiological and clinical features of Budd-Chiari syndrome in Japan. J Hepatol 1995;22:1-9.

8. Qi X, Yang M, Ren W, et al. Find duplicates among the PubMed, EMBASE, and Cochrane Library Databases in systematic review. PloS One 2013;8:e71838.

9. Wang J, Hu F, Qi X. Scientifc publications regarding liver cirrhosis and portal hypertension in 6 Science Citation Index Hepatology specialized journals from 2009 to 2011. J Liver: Dis Transplant 2013;2:2.

10. Qi X, Ren W, Liu L, et al. Prevalence of covert duplicate publications in Budd-Chiari syndrome papers in China: a systematic analysis. Am J Med 2013;126:633-639.e2.

11. Condat B, Pessione F, Helene Denninger M, Hillaire S, Valla D. Recent portal or mesenteric venous thrombosis: increased recognition and frequent recanalization on anticoagulant therapy. Hepatology 2000;32:466-470.

12. Condat B, Pessione F, Hillaire S, et al. Current outcome of porta vein thrombosis in adults: risk and benefit of anticoagulant therapy. Gastroenterology 2001;120:490-497.
13. Denninger MH, Chait $\mathrm{Y}$, Casadevall $\mathrm{N}$, et al. Cause of portal or hepatic venous thrombosis in adults: the role of multiple concurrent factors. Hepatology 2000;31:587-591.

14. Valla D, Casadevall N, Lacombe C, et al. Primary myeloproliferative disorder and hepatic vein thrombosis. A prospective study of erythroid colony formation in vitro in 20 patients with Budd-Chiari syndrome. Ann Intern Med 1985;103:329-334.

15. Valla DC. The diagnosis and management of the Budd-Chiari syndrome: consensus and controversies. Hepatology 2003;38:793-803.

16. Valla DC, Condat B. Portal vein thrombosis in adults: pathophysiology, pathogenesis and management. J Hepatol 2000;32:865-871.

17. Wang ZG, Zhang FJ, Yi MQ, Qiang LX. Evolution of management for Budd-Chiari syndrome: a team's view from 2564 patients. ANZ J Surg 2005;75:55-63.

18. Xu PQ, Ma XX, Ye XX, et al. Surgical treatment of 1360 cases of BuddChiari syndrome: 20-year experience. Hepatobiliary Pancreat Dis Int 2004;3:391-394

19. Darwish Murad S, Plessier A, Hernandez-Guerra M, et al. Etiology, management, and outcome of the Budd-Chiari syndrome. Ann Intern Med 2009;151:167-175.

20. Qi X, Wu F, Ren W, et al. Thrombotic risk factors in Chinese Budd-Chiari syndrome patients. An observational study with a systematic review of the literature. Thromb Haemost 2013;109:878-884.

21. Cheng D, Xu H, Lu ZJ, et al. Clinical features and etiology of Budd-Chiari syndrome in Chinese patients: a single-center study. J Gastroenterol Hepatol 2013;28:1061-1067.

22. Gao R, Liao Z, Li ZS. Scientific publications in gastroenterology and hepatology journals from Chinese authors in various parts of North Asia: 10-year survey of literature. J Gastroenterol Hepatol 2008;23:374378.

23. Qin B, Liang Y, Yang Z, Zhong R. Scientific publications on primary biliary cirrhosis from 2000 through 2010: an 11-year survey of the literature. PloS One 2012;7:e35366. 